\title{
A SHAPE MEMORY ALLOY BASED CRYOGENIC THERMAL CONDUCTION SWITCH
}

\author{
V.B. Kristnan', J.D. Singh ${ }^{1}$, T.R. Woodruff ${ }^{2}$, W.U. Notardonato ${ }^{2}$, \\ and $R$. Vaidyanathan ${ }^{1}$ \\ ${ }^{1}$ University of Central Florida \\ Orlando, Florida, 32816, USA \\ ${ }^{2}$ NASA Kennedy Space Center \\ Kennedy Space Center, Florida, 32899, USA
}

\begin{abstract}
Shape memory alloys (SMAs) can produce large strains when deformed (e.g., up to $8 \%$ ). Heating results in a phase transformation and associated recovery of all the accumulated strain. This strain recovery can occur against large forces, resulting in their use as actuators. Thus an SMA element can integrate both sensory and actuation functions, by inherently sensing a change in temperature and actuating by undergoing a shape change as a result of a temperature-induced phase transformation. Two aspects of our work on cryogenic SMAs are addressed here. First - a shape memory alloy based cryogenic thermal conduction switch for operation between dewars of liquid methane and liquid oxygen in a common bulkhead arrangement is discussed. Such a switch integrates the sensor element and the actuator element and can be used to create a variable thermal sink to other cryogenic tanks for liquefaction, densification, and zero boil-off systems for advanced spaceport applications. Second - fabrication via arc-melting and subsequent materials testing of SMAs with cryogenic transformation temperatures for use in the aforementioned switch is discussed.
\end{abstract}

\section{INTRODUCTION}

Shape memory alloys (SMAs) when deformed can produce strains as high as $8 \%$. Heating results in a phase transformation and associated recovery of all the accumulated strain, a phenomenon known as the shape memory effect. Thus SMAs are a unique class of alloys that "remember" and return to their original shape due to a thermally-induced phase transformation, following deformation. The strain recovery can occur against large forces, resulting in their use as actuators [1-4]. This principle is schematically shown in FIGURE 

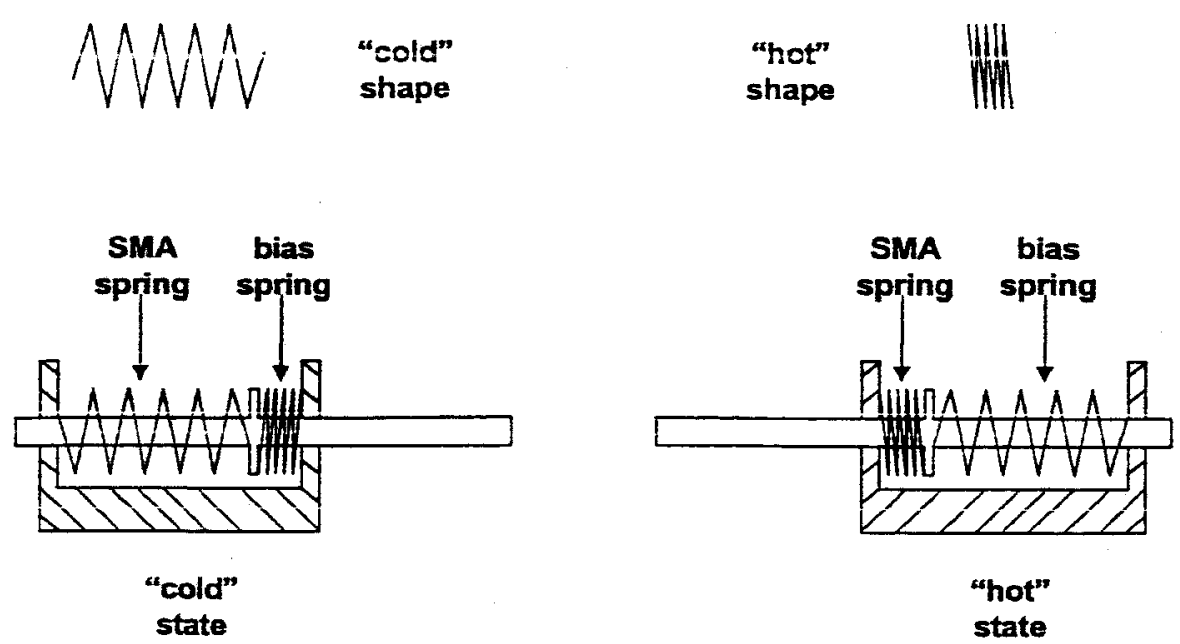

FIGURE 1. The shape memory effect and a simple switch based on this effect.

1. When the SMA element is exposed to an increase in temperature, it undergoes a phase transformation. Associated with this phase transformation is a shape change that constitutes the actuator displacement and can occur against an extemal force (e.g., a bias spring). Once the temperature retums to the initial level, the new phase is no longer stable and reverts to the original phase. This original phase being more compliant deforms easily and is now overcome by the bias spring. Potential applications include - flaps for directing airflow in air-conditioners, thermal switches for controlling coolant in automobiles, air dampers for multi-function electric ovens, thermal mixing valves in faucets, etc.

SMA actuators are particularly advantageous for space applications in that: (i) They integrate sensory and actuation functions. The SMA element inherently senses a change in temperature and actuates by undergoing a shape change as a result of a phase transformation. Consequently, the need for external electronic sensors and control is eliminated. (ii) They function in clean, debris-less, spark-free manner. The shape change that is responsible for the actuator displacement is again an inherent material property. It is not associated with moving parts that require lubrication or electrical signals with a potential to spark. (iii) They have high power/weight and stroke length/weight ratios. The operating range includes strain and stress limits of $8 \%$ and $700 \mathrm{MPa}$, respectively, depending on the number of required cycles. (iv) They posses the ability to function in zero-gravity environments with small, controlled accelerations. The displacement strains are a result of a thermally-induced phase transformation which can be controlled by the heat transfer rate (e.g., appropriate insulation).

The phase transformation that is usually responsible for strain recovery in SMAs is a reversible thermoelastic martensitic transformation. For example, in near equi-atomic NiTi the high temperature phase is a cubic (B2) austenitic phase while the low temperature phase is a monoclinic (B19') martensitic one. There is a temperature hysteresis associated with the forward and reverse transformations that ranges from $10-15 \mathrm{~K}$ for NiTiCu alloys, to $20-60 \mathrm{~K}$ for binary NiTi alloys, to $100 \mathrm{~K}$ for NiTiNb alloys $[5,6]$. Certain alloys also exhibit an intermediate thombohedral or R-phase transformation that is associated with a much lower transformation hysteresis, e.g., 1.5-2 K. The transformation temperature hysteresis depends on factors such as alloy composition, thermo-mechanical treatment, themal $z$ : ing and extemal loading.

While several alloy systems have been found to exhibit the shape memory effect, only those alloys that recover considerable amount of strain or can overcome substantial force 
during recovery are of commercial importance. These include NiTi alloys (Nitinol) and copper-based alloys such as CuAINi and $\mathrm{CuZnAl}$. Of these, NiTi-based alloys have found considerable use as actuators and in biomedical applications. NiTi is fairly sensitive to alloy element additives. Addition of $\mathrm{Fe}, \mathrm{Al}, \mathrm{Cr}, \mathrm{Co}$ or $\mathrm{V}$ (that tend to substitute $\mathrm{Ni}$ ) depresses the onset of the martensite phase transformation [7]. This depression is strongest with the addition of $\mathrm{Cr}$, while weakest with $\mathrm{V}$ and $\mathrm{Co}$. Their additions have practical importance in creating cryogenic SMAs, stiffening the austenitic phase, or in increasing the separation of the R-phase from the martensitic one [6].

\section{OBJECTIVE}

The oujective here was to design, consiruct and test an SMA thermai conduction switch (actuator) to facilitate thermal conduction of approximately 8 watts between two liquid reservoirs held at $118 \mathrm{~K}$ and $92 \mathrm{~K}$. Such a switch would control the liquid methane temperature and pressure in a zero boil-off system by allowing on demand heat transfer between two reservoirs kept at separate temperatures in an efficient and autonomous manner. It would also support methane liquefaction for future Mars missions in addition to fulfilling immediate requirements at NASA-Kennedy Space Center. Gas gap and liquid gap thermal switches that rely on convective heat transfer between two surfaces are currently being used as cryogenic range thermal switches. The sensors and active controls in such systems make them further complicated and expensive, yet less efficient than the proposed switch. Other systems using conduction bands make use of mechanical means to generate sufficient thermal contact and may not be reliable. SMA thermal switches have the potential to limit these problems.

\section{CONCEPT}

The initial design concept of the thermal conduction switch is shown in FIGURE 2. The design uses a bias spring in addition to an SMA spring for two-way actuation. A flexible copper strap provides the path for heat conduction when the switch is in the closed position. The SMA spring, sensing the temperature in the liquid methane tank, undergoes a phase transformation when the temperature in the liquid methane tank increases above a

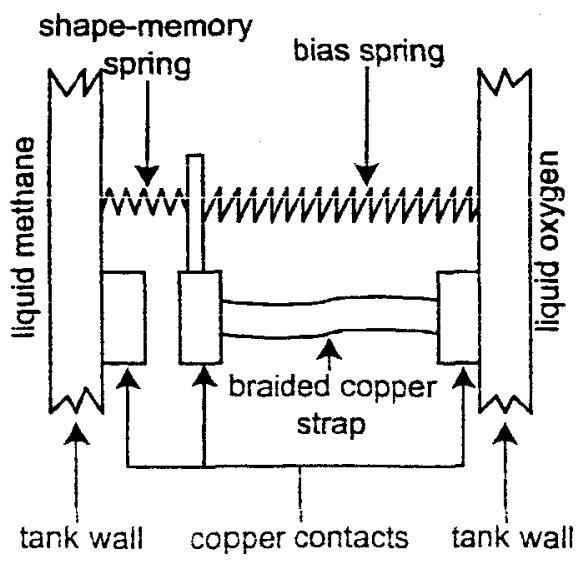

FIGURE 2. Concept for a shape memory alloy based cryogenic thermal switch. 
certain temperature. This phase transformation results in an increase in the SMA spring's stiffness, overcomes the bias spring and provides thermal contact between the two copper contacts. Indium foils are used between the copper contacts to limit the variation in thermal conductivity with contact force. The conductive heat path thus established through the flexible copper strap results in the liquid oxygen cooling the liquid methane. When the temperature of the liquid methane tank drops to the specified temperature, the SMA spring undergoes the reverse phase transformation. The resulting phase is more compliant and is overcome by the bias spring, thus breaking the heat conduction circuit.

\section{HEAT TRANSFER ANALYSIS}

In order to detemine the feasibility of the concept, finite element thermal analyses were carried out using TMG simulations in I-DEAS Master Series version 9 (Structural Dynamics Research Corporation). Both steady state and transient analyses were carried out. The objective of the steady state analysis was to determine the temperature profile of the SMA element and the moving thermal contact when the switch is in the closed position (i.e., when thermal contact is made) and the temperature of methane in the tank is above the required holding temperature. The transient analysis was carried out to study the response time.

An assembly model was constructed and meshed to represent the geometry of the prototype discussed in the next section. The stationary copper contact was assumed to be in equilibrium with the methane tank and the effects of convection and radiation were ignored. The initial temperanure of the assembly was arbitrarily set between $119 \mathrm{~K}$ and 120 $\mathrm{K}$, the methane tank at $120 \mathrm{~K}$ and the oxygen tank at $92 \mathrm{~K}$. The steady state gradient in the SMA element was relatively uniform with an average temperature of $108 \mathrm{~K}$. The transient response gave a response time of $2.5 \mathrm{hrs}$. The feasibility of the target goal of $8 \mathrm{~W}$ was also confirmed. Thus a heat leak of $2 \mathrm{~W}$ in a $25 \mathrm{~L}$ dewar resulted in methane gaining $2 \mathrm{~K}$ in about 10.4 hours while the liquid oxygen needed 3.5 hours to cool the methane by $2 \mathrm{~K}$. An important output of the thermal analyses was that attention had to be paid in the placement of the SMA element relative to the oxygen tank.

\section{IMPLEMENTATION}

The aforementioned concept was implemented in two prototypes. The first prototype successfully demonstrated the feasibility of the concept in a switch that operated between ice water $(273 \mathrm{~K})$ and hot water $(338 \mathrm{~K})$ using commercially available NiTi and is outlined in Ref. [8]. Another prototype was fabricated for testing in cryogenic vacuum conditions and incorporated SMA elements in spring forms. Various issues that were addressed in the design of the thermal conduction switch included: (i) hysteresis of the SMA element; (ii) the developing temperature gradient over the length of the SMA element when the switch is in the closed condition; (iii) contact resistance for efficient and reliable heat transfer, as the switch is expected to work in vacuum conditions; (iv) and contact force generated by the SMA element. These issues were respectively addressed by positioning both the SMA element and bias spring on the same side, using insulation at one end of the element, using indium foil between the mating surfaces and by controlling the phase transformation.

Two approaches were used to fabricate the SMA elements. The first relied on commercially available SilA alloys and consequently did not have optimal transformation temperatures. The second relied on the development of ternary cryogenic NiTiFe alloys and 
is discussed in the next section. All the materials for the construction of the prototype were selected by keeping in mind issues of low-temperature embrittlement and thermal conductivity. These materials included pure copper, brass, beryllium-copper alloys, austenitic stainless steels containing more than $7 \%$ nickel and polytetrafluoroethylene (Teflon). Furthermore, indium foil and Apiezon ${ }^{\otimes} \mathrm{N}$ grease were used to enhance the thermal conductivity between mating parts. The fabrication of the SMA elements involved shape-setting and subsequent heat treatments. Shape-setting of an SMA element refers to the process of setting the original or parent shape that the element will return to on heating. Shape setting is done by constraining the SMA element into a required shape using a fixture or mandrel and then heating it to temperatures of around $673 \mathrm{~K}$ to $773 \mathrm{~K}$ for 1 to 20 minutes depending on the size of the element. Following SMA spring theory $[9,10], 0.216$ $\mathrm{cm}$ diameter NiTi wire (56.1 wt.\% Ni nominal composition) was set into 3 coils, with each coil being $2.6 \mathrm{~cm}$ in diameter, in order to obtain a maximum recovery force of $16 \mathrm{~N}$ and a stroke of $1 \mathrm{~cm}$. The shape setting was carried out at $673 \mathrm{~K}$ for 20 minutes. Subsequent heat treatments included a solution treatment followed by an ageing treatment. Solution treatment was done in a vacuum at $1073 \mathrm{~K}$ for 2 hours followed by quenching in oil. Ageing treatment was done in a vacuum at $973 \mathrm{~K}$ for 1 hour followed by quenching in oil. The lowest transformation temperature (peak) achieved as a result of the heat treatment was $213 \mathrm{~K}$ with a hysteresis of $35 \mathrm{~K}$. The NiTi springs were subsequently tested for stiffness in the hot and cold conditions. The results are shown in FIGURE 3. From the values of stiffness in the hot and cold states, the stiffness of the bias spring was calculated for the deflection required $[9,10]$. The prototype is shown in Figure 4 , while the technical specifications and testing results are forthcoming in Ref. [11].

\section{CRYOGENIC SHAPE MEMORY ALLOY DEVELOPMENT}

The thermal treatments of commercially available NiTi shape memory alloys in the preceding section were optimized to obtain the lowest transformation temperatures. However, the lowest transformation temperatures achieved did not meet requirements for the switch. Consequently, an effort is ongoing by the authors to develop cryogenic NiTiFe

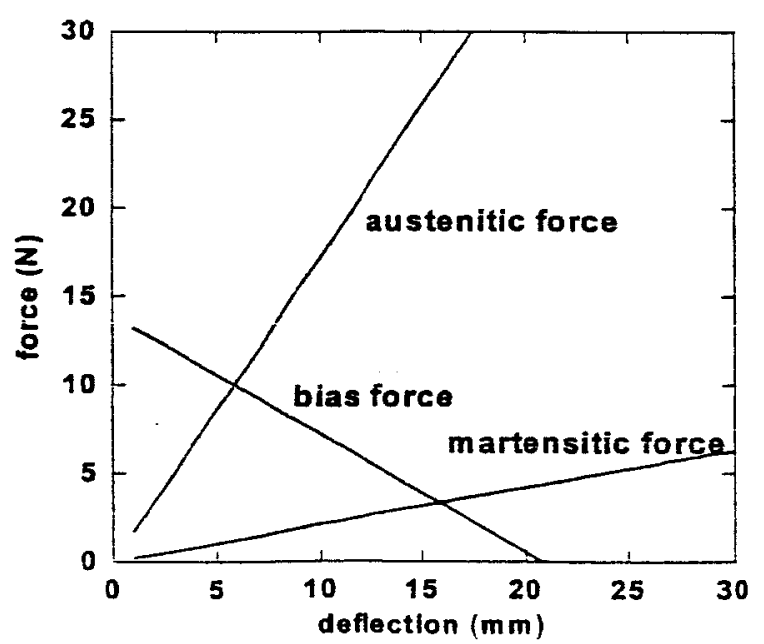

FIGURE 3. Defection as a function of force for the bias spring and the NiTi spring in hot (austenitic) and cold (martensitic) conditions. 


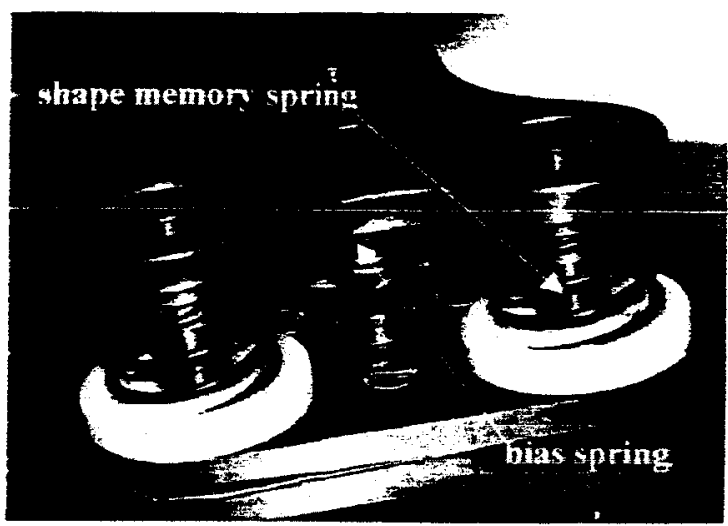

FIGURE 4. A prototype shape memory alloy based cryogenic thermal switch.

shape memory alloys for the thermal conduction switch presented here.

Previously, NiTiFe based shape-memory alloy couplings were widely used to connect titanium hydraulic tubing in Grumman F-14 aircrafts. Given the operating temperature of these aircrafts, the couplings were deformed and stored in liquid nitrogen $(77 \mathrm{~K})$. At the time of application, a coupling was introduced to join two tubes at room temperature. The increase in temperature resulted in a phase transformation (at around $120 \mathrm{~K}$ ) and the shape change associated with the phase transformation decreased the coupling diameter. This decrease in diameter exerted a stress on the tubes and resulted in a secure joint.

The approach to develop a cryogenic NiTiFe shape memory alloy for use in the thermal conduction switch presented here relies on varying the alloy composition. Additionally, the narrow hysteresis thombohedral or R-phase transformation is being used. High purity powders of $\mathrm{Ni}, \mathrm{Ti}$ and $\mathrm{Fe}$ in varying ratios are thoroughly mixed in a ball mill. Small buttons weighing 0.010 to $0.025 \mathrm{Kg}$ are then made from the blended powders by arcmelting in an IVI Corp. Mark-14 Vacuum/controlled atmosphere furnace (see FIGURE 5a). The resulting buttons (FIGURE $5 \mathrm{~b}$ ) are then thermo-mechanically processed to produce strips that are shown in FIGURE 5c. The strips are tested for their transformation temperatures using dilatometery and differential scanning calorimetery. FIGURE 6 demonstrates the shape memory effect in an alloy processed via the aformentioned route. A clamp weighs down the NiTiFe strip when it is dipped in liquid nitrogen (FIGURE 6a). As the setup warms up to room temperature, the phase transformation results in it straightening out (FIGURE 6b). The stress due to the transformation overcomes $45 \mathrm{MPa}$ in this case.

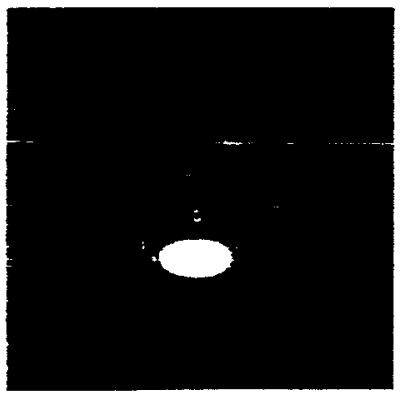

(a)

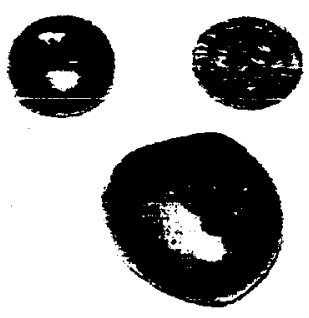

(b)

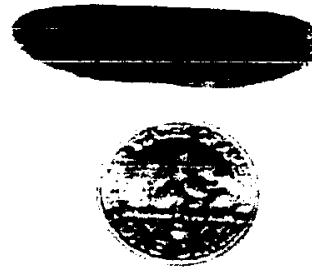

(c)

FIGURE 5 . Processing of NiTiFe allovs. Arc melting of NiTiFe powders in (a) to form buttons in (b) which are subsequently thermo-mechanicaily processed to give elements in (c). Such a strip element is tested in FIGURE 6. 


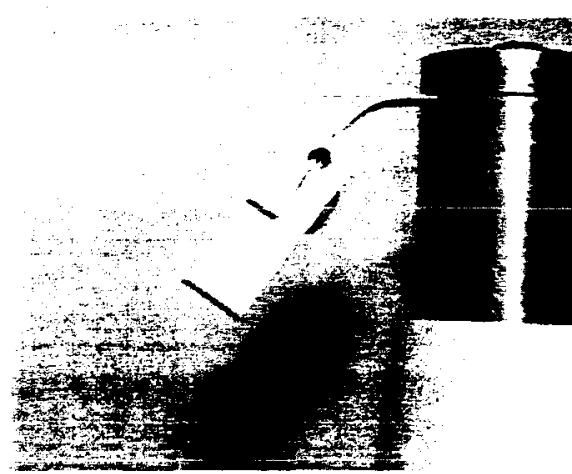

(a)

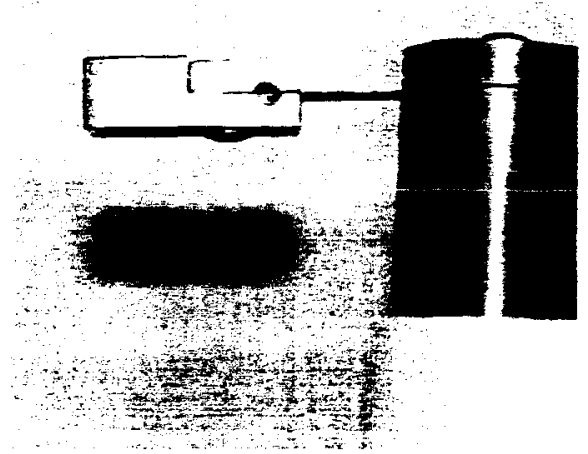

(b)

FIGURE 6. Demonstration of a cryogenic shape memory actuator.

\section{CONCLUSIONS}

The concept and prototype for a shape memory alloy based cryogenic thermal conduction switch for operation between dewars of liquid methane and liquid oxygen in a common bulkhead arrangement has been presented. Such a switch integrates the sensor element and the actuator element and can be used to create a variable thermal sink to other cryogenic tanks for liquefaction, densification, and zero boil-off systems for advanced spaceport applications. Work is ongoing to develop a cryogenic shape memory alloy that meets the required transformation temperatures and can be implemented in a prototype switch. To date a total of 21 compositions and heat treatments have been attempted with significant knowledge gained on the relationship between transformation temperatures, composition and thermo-mechanical processing. The cryogenic alloys developed have potential use as shape-memory alloy actuator elements for seals, valves, debris-less separation mechanisms, latch and/or release mechanisms, fluid-line repair and self-healing gaskets.

\section{ACKNOWLEDGEMENTS}

This work is supported by grants from NASA Glenn Research Center (through the Florida Solar Energy Center) and NASA Kennedy Space Center.

\section{REFERENCES}

1. Funukubo, H., Shape Memory Alloys, Gordon and Breach Science Publishers, New York, 1987.

2. Schetky, L.M., "Shape Mernory Alloy Applications in Space Systems", in Engineering Aspeczs of ShapeMemory Alloys, edited by Duerig. T. W., Melton, K. N., Stockel, D. and Wayman, C. M., ButterworthHeinemann, London, 1990, pp. 170 - 178.

3. Otsuka, K. and Wayman, C.M., (eds.) Shape Memory Materials. Cambridge University Press, 1998.

4. Vaidyanathan, R., "Shape-Memory Alloys", in Kirk-Othmer Encyclopedia of Chemical Technology, Wiley laterScience, John Wiley \& Sons Inc., New York, 2002 edition.

5. Suzuki, Y. and Horikawa H., "Thermal hysteresis in Ni-Ti and Ni-Ti-X alloys and their applications", Materials Research Society Symposium Proceedings 246, 1991, pp. 389-398.

6. Duerig, T.W. and Pelton, A.R., "Ti-Ni Shape Memory Alloys", in Material Properties Handbook: Titonium Allovs, ASM International. 1994. pp. 1035-1048.

7 Guldstein. D.M., Buehler, W. J. and Wiley, R.C., "Effects of Alloying upon Certain Properties of Nitinol". V()LLTR 64. 1964, p. 235. 
8. Droney, M., Kaiboussi, N., Lemanski, J., Rodriguez, C. and Woodruff, T., Senior Design Project Report, "Shape Memory Alloy Thermai Swirch", University of Cenuai Fionda, 2003.

9. Ohkata, I. and Suzuki, Y., "The Design of Shape Memory Alloy Actuators and their Applications", in Shape Memory Materials, edited by Otsuka, K. and Wayman, C. M., Cambridge University Press, 1998, pp. $240-266$

10. Waram, T, "Design Principles For Ni-Ti Actuators", in Engineering Aspects of Shape-Memory Alloys, edited by Duerig, T. W., Melton, K. N., Stockel, D. and Wayman, C. M., Butterworth-Heinemann, London, 1990, pp. 234 - 244.

11. Krishnan, V. B., Masters Thesis, "Design, Fabrication and Testing of a Shape Memory Alloy based Cryogenic Thenmal Conduction Switeh", University of Central Florida, 2003. 